\title{
ENSAYOS
}




\section{Los fines de la educación en el siglo XXI. Una respuesta desde la pedagogía de John Dewey (1859-1952)}

Dra. Virginia Guichot Reina*

\section{RESUMEN}

Una pregunta fundamental para cualquier docente es aquella que se refiere a los fines de la educación: ¿para qué educamos? Este interrogante apunta al tipo de ser humano que cada sociedad considera como deseable, el que responde a los valores más apreciados en ese momento histórico. En los albores del siglo XXI, parece que se generaliza en todo el mundo occidental la búsqueda del ciudadano democrático pero, a veces, se percibe la falta de una reflexión profunda sobre su contenido, es decir, acerca de las virtudes o cualidades que debería poseer.

En este artículo, intentamos una aproximación a las finalidades que ha de plantearse la educación cara al siglo XXI a partir de la pedagogía de John Dewey (1859-1952). Para ello, analizamos su concepto de educación y de fin educativo y, por último, establecemos la vigencia de sus ideas en nuestros días.

\section{SUMMARY}

The issue of aims of education is essential for educators: What do we educate for? This problem refers to the person that each society considers as desiderable, a person with the values more estimated at this moment of History. At the beginning of the 21 th. century, there is a quest for a democratic citizen in the Western World but, sometimes, there is a lack of a profound reflection about its content, i.e., democratic virtues or qualities.

In this paper, using John dewey's pedagogy, we try to approach the aims that an educator should seek in the 21 th. century. We analyse his concepts of "education" and "educational aim" and, finally, we establish the validity of his ideas today.

\section{Descriptores}

Pedagogía - Filosofía de la educación - Socialización política - Democracia.

\section{Key words}

$$
\text { Pedagogy - Philosophy of education - Political socialization - Democracy. }
$$

\section{INTRODUCCIÓN}

Una pregunta clave para cualquier filósofo de la educación es aquella que se refiere a los fines, al para qué de todo el proceso educativo, a la meta hacia la que se encamina. En cada época, en cada cultura, se han dado respuestas distintas acordes a la mentalidad del momento, a las exigencias que la sociedad plantea. Incluso cuando se ha resumido el fin en asegurar la formación integral de la persona, tal descripción ha reclamado una reflexión mucho más profunda: ¿qué planos o dimensiones comprende esa "formación integral"?, ¿se le otorgan a todas las facetas la misma importancia?, ¿cuáles son los valores que se consideran característicos de la persona? Son cuestiones que originan respuestas dispares según el momento histórico; interrogantes

\footnotetext{
* Departamento de teoría e historia de la educación y pedagogía social, Universidad de Sevilla. 
difíciles y, para algunos, "molestos" porque obligan en muchas ocasiones a replantear temáticas tan esenciales como el sentido de la vida, el por qué de la existencia o de nuestros deberes como humanos, $y$, sin embargo, interrogantes ineludibles para cualquier persona que se tome en serio ese proceso en el que todos estamos inmersos como es el de la educación.

Nos encontramos en los albores del siglo XXI, dentro de lo que se suele denominar la era de las telecomunicaciones. Nos hallamos en un mundo donde se ha producido el boom de los mass-media, una eclosión de faxes, teléfonos móviles, módems, Internet..; un mundo que está exigiendo nuevos desafíos para el educador que le impelen a reflexionar sobre el para qué de su trabajo, sobre el Norte al que dirigir todas y cada una de sus actividades, de modo que apunten a ese modelo de persona que aspira a crear. Sin duda, buscará un ser humano que posea las competencias necesarias para vivir en este siglo veintiuno. Para ello, ha de partir de un concepto de educación y preguntarse por la finalidad de la misma.

En este artículo, intentamos responder a este interrogante crucial del para qué educar a través de la propuesta de una de las figuras cumbres de la pedagogía contemporánea, John Dewey (1859-1952). En los inicios del siglo XXI, su mirada crítica, sus reflexiones sobre el mundo educativo siguen conservando su fuerza vital, como suele ocurrir con los grandes genios. Desde su concepto de educación como reconstrucción constante de la experiencia, analizamos su idea de fin de la educación como capacidad continuada de desarrollo. Descrito este marco teórico, pretendemos extraer aportaciones que consideramos muy valiosas cara al panorama educativo de nuestros días.

\section{EL CONCEPTO DE "EDUCACIÓN" DE JOHN DEWEY: RECONSTRUCCIÓN CONTINUA DE LA EXPERIENCIA}

En A Cyclopedia of Education (1911), John Dewey nos proporciona una definición genérica de educación como la suma total de procesos por medio de los cuales una comunidad o grupo social transmite su bagaje cultural y metas con vista a asegurar su existencia y desarrollo continuos ${ }^{1}$. Asimismo, destaca la necesidad de educación en tres planos: socioético, biológico y psicológico. El primero se refiere a la exigencia de perpetuación, de continuidad de la sociedad; el segundo, a la existencia de seres inmaduros que necesitan ser orientados en su crecimiento; el último - estrechamente relacionado con los anteriores - a la formación del carácter de un ser auténticamente "humano", con capacidad crítica, reflexiva, solidario con los demás. Sin embargo, si nos quedásemos aquí, o incluso si añadiésemos la definición propia que en la obra citada da del término "educación", como un proceso de continua reconstrucción de la experiencia con el propósito de ensanchar y profundizar su contenido social, mientras que al mismo tiempo, el individuo adquiere el control de los métodos implicados ${ }^{2}$, no podríamos contemplar la riqueza del análisis deweyano de este concepto clave en su pensamiento. Es por ello por lo que resulta conveniente acudir a una de sus obras pedagógicas más representativas, Democracia y Educación (1916), cuyo subtítulo es Una introducción a la Filosofía de la Educación, donde expone amplia y lúcidamente las notas características

\footnotetext{
${ }^{1}$ La mayor parte de los escritos de John Dewey consultados se han extraído de las obras completas, que han venido publicándose 3333por la Southern Illinois University Press, de 1967 a 1991, hasta completar un número de treinta y siete ejemplares. Se organizan en tres apartados: Early Works (E.W.), Middle Works (M.W.) y Later Works (L.W.), que es ya la clasificación canónica para citar sus trabajos. La referencia completa es: The Collected Works of John Dewey, 1882-1953, editados por Jo Ann Boydston, Carbondale and Edwardsville. Southern Illinois University Press, 1969-1991.

DEWEY, J.: Definición de education. A Cyclopedia of Education. O.C./ M.W. 6: p. 425.

${ }^{2}$ Ibídem. p. 431.

Digitalizado por RED ACADEMICA
} 
de tal término y su postura personal que supone la apuesta por una concepción de la educación como reconstrucción continua de la experiencia ${ }^{3}$.

En opinión de Delédalle, la máxima originalidad de la pedagogía deweyana radica en la aplicación del principio de continuidad a la educación que, hasta cierto punto, se puede hacer remontar a la psicología genética de James y Hall y al vitalismo de Trendelenburg ${ }^{4}$. En Dewey, se aprecia que la continuidad tiene dos dimensiones: ontogenética, reconstrucción a lo largo de toda la vida y, en este plano, sería uno de los primeros en explicitar el valor formativo de toda la experiencia vital; histórica, reconstrucción inter y transgeneracional de la experiencia, en el sentido evolucionista del término.

\section{II.1. Individuo, sociedad y comunicación. La educación, instrumento de cohesión social}

La educación es un fenómeno característico del ser humano por lo que para comprender el análisis deweyano hemos de tener presente su visión antropológica. Hablar de hombre es hablar de vida, es referirnos a un ser que, como toda criatura viviente, se esfuerza primeramente por asegurar su propia conservación, por renovarse o, para ser más exactos, por autorrenovarse, utilizando como instrumento, como herramienta con vistas a conseguir esa finalidad básica, la actuación sobre el entorno que lo rodea. La vida es un proceso de autorrenovación mediante la acción sobre el medio ambiente ${ }^{5}$. Dewey, con una perspectiva darwinista, no se refiere sólo al nivel ontogenético, sino que se extiende hasta la filogénesis; no piensa únicamente en el ser individual sino en la sociedad. La palabra vida designa toda la extensión de la experiencia, tanto de la "raza" (race) o género humano - por emplear un término que nos resulte más cercano - como del sujeto en su individualidad, y es así como incluye costumbres, instituciones, creencias, ritos, y todo aquello que nosotros podríamos introducir en el concepto de cultura o espíritu de un pueblo o de una persona. Vida, experiencia, palabras ricas en significado, conceptos claves dentro de la filosofía deweyana, estarán relacionadas directamente con el término educación, pues ésta no es sino el medio por excelencia para asegurar la continuidad de ambas.

Para el ser humano, no se entiende la vida sin semejantes, sin otros sujetos que lo rodeen; su existencia es siempre social, y una sociedad únicamente se puede mantener gracias a un proceso de transmisión, a una comunicación de hábitos de hacer, pensar y sentir, de los más viejos a los más jóvenes. Esa comunicación, ese compartir experiencias, esa creación de un fondo común de significados, de un espíritu o inteligencia colectivo, es la esencia de todo grupo social, hasta el punto de que Dewey llega a afirmar que la sociedad no sólo continúa existiendo por la transmisión, por la comunicación, sino que existe en la transmisión y en la comunicación ${ }^{6}$. Una comunidad supone objetivos, creencias, aspiraciones compartidas, una cierta "semejanza mental". El instrumento mediante el cual logramos poseer ese bagaje común es la comunicación y toda ella - dirá el propio Dewey - es educativa. El proceso de convivir enriquece nuestras experiencias, estimula nuestra imaginación, nos ayuda a alcanzar esa empatía,

\footnotetext{
${ }^{3}$ Democracia y Educación (1916) será el libro central al que se acudirá para acercarnos a la idea deweyana de educación.

${ }^{4 " C e}$ qui appartient en propre à Dewey et qui fait l'originalité de sa pédagogie est l'application du principe de continuité à l'éducation, application qui conduisit Dewey à proposer une nouvelle structure scolaire et de nouvelles méthodes et de nouveaux programmes d'enseignements - structure, méthodes et programmes qui furent expérimentés à l'Ecole laboratoire de 1896 à $1904 . "$ DELEDALLE, G.: L'idée d'expérience dans la philosophie de John Dewey. Presses Universitaires de France. Tunis. p. 225.

${ }^{5}$ DEWEY, J.: Democracia y educación. Ed. Morata. Madrid, 1995. cap.1. p. 13.
} 
ese saber ponerse en el lugar de otro, que autores de nuestros tiempos como Piaget y Kölhberg sitúan como condición básica para llegar a los más altos niveles de desarrollo intelectual y moral. Educación, comunicación y vida social, serán tres conceptos estrechamente ligados en la pedagogía deweyana:

"No sólo la vida social es idéntica a la comunicación, sino que toda comunicación (y por tanto toda vida social auténtica) es educativa. Ser un receptor de una comunicación es tener una experiencia ampliada y alterada. Se participa en lo que otro ha pensado y sentido, en tanto que de un modo restringido o amplio se ha modificado la actitud propia. Realizad la experiencia de comunicar, con plenitud y precisión, alguna experiencia a otro, especialmente si es algo complicado y encontraréis que ha cambiado vuestra propia actitud respecto a vuestra experiencia. La experiencia debe formularse para ser comunicada. Para formularla se requiere salir de ella, verla como la vería el otro, considerar los puntos de contacto que tiene con la vida de otros, para que pueda adquirir tal forma que aquél sea capaz de apreciar su sentido. Salvo cuando se trata de lugares comunes y frases hechas, tenemos que asimilarnos, imaginativamente, algo de la experiencia de otros con el fin de hablarle inteligentemente de nuestra propia experiencia."

Es la comunicación la que asegura la transmisión de experiencias, la ampliación de las propias, la ayuda al enriquecimiento de las ajenas, y ésta se realiza en gran parte gracias al lenguaje que, en el caso del ser humano, está dotado de unas funciones que lo distancian de cualquier otro utilizado por el resto de los seres vivos y que lleva a caracterizar a la persona como animal simbólico por excelencia ${ }^{8}$. El simple hecho de convivir educa - lo que en nuestros términos aludiría a la educación informal y en palabras deweyanas a la denominada educación indirecta o incidental - pero, a medida que las sociedades se hacen más complejas en su estructura y recursos, aumenta la necesidad de la enseñanza y el aprendizaje sistemático o intencional. Surge entonces la escuela como institución específicamente educativa.

El medio social se nos presenta, pues, como educativo, un medio donde el proceso básico es el de la comunicación, donde prima la categoría que Kant elevó al rango más alto, la de relación. El ambiente social forma la disposición mental y emocional de la conducta de los individuos a través de las expectativas, exigencias, aprobaciones y condenas de los demás. Sin duda, bajo la visión deweyana, estamos condicionados - no determinados - por el grupo social donde transcurre nuestra existencia, y ello se deja ver con claridad en varias facetas, de las que Dewey destaca el vocabulario que empleamos, nuestra forma de hablar, las maneras o "saber-estar", el buen gusto y la apreciación estética, y, especialmente, las normas más profundas de los juicios de valor:

\footnotetext{
"Puede decirse que las cosas que aceptamos sin indagación o reflexión son justamente las cosas que determinan nuestro pensar consciente y deciden nuestras resoluciones. $Y$ estos hábitos que se hallan bajo el nivel de la reflexión son precisamente aquellos que se han formado en el dar y tomar constantes de las relaciones con los demás."9
}

Dewey concederá una importancia de primer orden al ambiente donde se desenvuelve el individuo hasta el punto de afirmar: "Nosotros nunca educamos directamente, sino de forma indirecta por medio del ambiente"10. Unicamente controlando el medio físico y social conseguiremos la correcta formación de los sujetos. Se va a explicar de este modo la aparición de la escuela como medio ambiente especial, que John Dewey liga a la presencia de la escritura, de los símbolos escritos. Llega un momento en que la complejidad de las condiciones sociales es tal que se confía al lenguaje escrito una parte considerable del caudal social. Los símbolos escritos no

\footnotetext{
${ }^{7}$ DEWEY, J.: Democracia y educación. op. cit. pp. 16-17.

${ }^{8}$ DEWEY, J.: "Challenge to liberal thought". Problems of Men. Ed. Philosophical Library. Inc. New York. 1946. p. 149.

${ }^{9}$ DEWEY, J.: Democracia y Educación, op. cit. p. 28.

${ }^{10}$ Ibídem. cap. 2. p. 28.

Digitalizado por RED ACADEMICA
} 
pueden ser obtenidos en el intercambio accidental con los demás seres y, además, las formas escritas tienden a seleccionar y registrar materias que son relativamente extrañas a la vida cotidiana. Se hace necesaria la creación de una institución específica con un propósito claramente educativo: la escuela.

La institución escolar gozará para Dewey de tres funciones que la distinguen de otras asociaciones ordinarias de la vida. La primera de ellas es la de simplificar el ambiente y ordenar los factores que fomenten las disposiciones que se desea desarrollar. La escuela selecciona los rasgos fundamentales de las civilizaciones complejas, aquellos que se estiman como positivos de cara a la mejor adaptación al medio, y después establece un orden progresivo, utilizando los conocimientos que se van adquiriendo como soporte e instrumento para obtener los que se consideran de mayor dificultad. En segundo lugar, elimina, en la medida de lo posible, los rasgos perjudiciales del medio ambiente existente, para que no influyan sobre los hábitos mentales, es decir, intenta que no penetren en su interior los estímulos negativos que fomenten disposiciones no idóneas, como por ejemplo, la creación de individuos violentos, racistas, intolerantes. Por último, y complementando lo anterior, ha de procurar crear un ambiente más amplio y mejor equilibrado que aquél por el cual el sujeto sería probablemente influído, o sea, debe de esforzarse por enriquecer su contexto vital, por alcanzar para todos una igualdad real de oportunidades, por hacer comprender que el género humano no se reduce a nuestra comunidad más cercana, por facilitarnos la toma de conciencia de que somos ciudadanos del mundo.

La institución escolar posee el rol fundamental de orientar las tendencias activas de los individuos conforme a un cierto plan continuo, que, en definitiva, tiene como misión el asegurar el constante crecimiento del ser humano como persona. Ahora bien, Dewey recalca que cualquier intento de dirección ha de partir de la base de la materia prima con la que se cuenta, es decir, en este caso, del conocimiento de cuáles son los instintos y los hábitos existentes en aquellos a los que se quiere dirigir ${ }^{11}$. Se entiende así la importancia de una ciencia como la psicología en materia de educación: sólo conociendo las energías que operan en un momento dado podrán ser eficaces las tentativas de dirección. Cualquier dirección es re-dirección: desvía las actividades que iban ya por otro canal.

La forma de control más importante y permanente por parte del grupo social de la actuación del sujeto es - de acuerdo con el pragmatismo - los modos cómo las personas con quienes está asociado usan las cosas, los instrumentos con los cuales realizan sus propios fines, que no es sino la existencia como tal del medio social. Para el pragmatismo, lo que proporciona el significado a los objetos es el uso característico que se les otorga. Directamente relacionado con este método de control social, se halla la explicación del proceso de imitación que nos proporciona Dewey. Rechaza la idea difundida por la psicología social entonces en boga que suponía la existencia de un instinto imitativo que conduciría a que el joven se dedicase espontáneamente a adaptarse a las normas establecidas por los otros y reproducirlas en su propio esquema de conducta. Para el filósofo, los defensores de esta postura toman un efecto por su causa, ponen la carreta delante de los bueyes. Según lo anteriormente expuesto, para Dewey, lo que se llama el efecto de la imitación es principalmente el producto de la

\footnotetext{
${ }^{11}$ En este sentido, Dewey comenta que la dirección puramente externa es imposible. El ambiente podrá proporcionar estímulos para provocar respuestas pero éstas proceden de tendencias que ya posee el individuo: "Aún cuando una persona se asuste de amenazas para que haga algo, en realidad, la amenaza es eficaz solamente porque la persona tiene el instinto de miedo." Ibídem. p. 34. Esta posición es ya netamente constructivista, perspectiva que tiene su origen en la década de los treinta, pero que tardaría casi medio siglo en imponerse. 
instrucción consciente y del influjo selectivo ejercido por la confirmación y la ratificación inconsciente de aquellos con quienes nos asociamos, expresa el hecho de compartir con otros el uso de las cosas que llevan a consecuencias de interés común ${ }^{12}$. Se entiende así que John Dewey considere la imitación de los medios de realización, un acto inteligente. Supone una observación rigurosa y una juiciosa selección que nos capacitará para cumplir mejor los fines que nos hemos propuesto.

La educación se ocupará de lograr esa "inteligencia común" de los medios y de los fines de la acción, esa identidad de intereses que caracteriza a una comunidad, a cualquier grupo social. Si los libros y la explicación del docente son recursos que pueden - y deben - ser utilizados cara a obtener esos objetivos, no serán, para Dewey, los fundamentales. Este será un defensor acérrimo de introducir en las escuelas más actividades conjuntas donde intervengan los alumnos ya que piensa que es la mejor forma de que éstos puedan adquirir un sentido social de sus propias capacidades y de los materiales empleados, por lo que, de nuevo, insiste en la importancia del cuidado del ambiente, que ha de contar con recursos que permitan la actividad compartida.

\section{II.2. Crecimiento y desarrollo, claves de todo proceso educativo}

Al orientar las conductas de los nuevas generaciones en una cierta dirección, la sociedad determina su propio futuro, se asegura su crecimiento, término que Dewey siempre relacionará con el de educación desde el momento en que se entiende fundamentalmente como capacidad de desarrollo. El crecimiento tiene como condición primaria la inmadurez que no ha de ser considerada negativamente, como ausencia de poderes que puedan existir en un momento posterior, sino desde la vertiente positiva, capacidad de crecer. Dewey recuerda que una de las causas de esa visión negativa de la inmadurez es el tratar siempre la infancia en comparación con la etapa adulta y no darle valor por sí misma ${ }^{13}$.

Los rasgos principales de la inmadurez son la dependencia y la plasticidad. En cuanto a la primera, la indefensión que, sobre todo a nivel físico, parece sugerir, se compensa con la posesión por parte de los niños de un equipo puntero para el intercambio social. La incapacidad de controlar las objetos físicos está acompañada de una intensificación de interés y de atención respecto a las conductas de los seres humanos. Los impulsos del niño tienden a facilitar la respuesta social ${ }^{14}$.

Respecto a la plasticidad, Dewey se muestra partidario de la doctrina de la prolongación de la infancia propuesta por John Fiske ${ }^{15}$. Este autor señalaba el hecho de que la temprana perfección y la alta especialización de las funciones son desfavorables para un desarrollo posterior de forma que éstas harían prácticamente imposible la adquisición de nuevas capacidades. En cierto sentido, la pronta madurez de los poderes e instintos en los animales es la barrera que excluye el aprendizaje y por ende, el

\footnotetext{
${ }^{12}$ Ibídem. cap. 3. p. 41.

${ }^{13}$ DEWEY, J.: Definición de Infancy, Theory of. Cyclopedia of Education, O.C./ M.W. 7: p. 246. Autores anteriores habían incidido en este punto, cada vez más claro gracias a los avances científicos, en biología y psicología. Rousseau, en el Emilio (1762), hizo especial hincapié en darle valor propio a la etapa infantil: "La humanidad tiene su lugar en el orden de las cosas; la infancia tiene también el suyo en el orden de la vida humana; es preciso considerar al hombre en el hombre, y al niño en el niño. Debemos asignar a cada uno su lugar y fijarle en el mismo, ordenar las pasiones humanas según la constitución del hombre, y es todo esto lo que podemos hacer para su bienestar." ROUSSEAU, J.J.: Emilio. libro II. EDAF. Madrid. 1972. p. 123.

${ }^{14}$ DEWEY. J.: Democracia y Educación. op. cit. cap. 4. pp. 47-48.

${ }^{15}$ FISKE, J.: The Meaning of Infancy. Boston. 1909. Dewey lo cita en el capítulo cuarto de Democracia y Educación (1916). 
desarrollo. La incompetencia para actos especializados del joven humano significa una plasticidad que permite y demanda aprendizaje - adaptación - de las capacidades a las nuevas condiciones. La inmadurez aparece como el poder de desarrollo continuo, de readaptación al cambio; representa el ímpetu evolutivo versus la fijación de la capacidad de adaptación indicada por los órganos maduros.

La plasticidad es, para Dewey, la capacidad para aprender de la experiencia, el poder para retener de ella algo que sea eficaz para afrontar las dificultades de una posterior situación. Conlleva la posibilidad de modificar las acciones sobre la base de los resultados de experiencias anteriores, es decir, de contraer hábitos, disposiciones específicas. La educación puede ser definida como la adquisición de ciertos hábitos que efectúan un ajuste del individuo y su ambiente, entendido tal ajuste en un sentido activo, de control de medios para la consecución de fines. Es decir, no se trata de lograr, gracias al proceso educativo, una "conformidad" al ambiente ni éste debe ser visto como algo fijo que proporciona el fin y la norma de los cambios que tienen lugar en el organismo. En tal caso, nos enfrentaríamos a una concepción de ajuste como adaptación del sujeto a esta fijeza de condiciones, lo que, técnicamente, a veces se designa como "acomodación".

Dewey insiste en la adaptación activa, en la capacidad del organismo para modificar el ambiente que lo rodea. En este sentido, distingue entre los hábitos rutinarios o hábitos sin pensamiento, donde no intervienen factores intelectuales, de observación y de reflexión, y los hábitos de grado superior, donde juega un papel de primer orden el intelecto. Los primeros suelen degenerar en modos de acción que nos esclavizan en la medida en que la inteligencia se ha desconectado de ellos; nos poseen a nosotros en vez de poseerlos nosotros a ellos y ponen fin a la plasticidad. Una metodología educativa que haga hincapié en la rutina y en la repetición mecánica para asegurar la eficacia externa del hábito, de la destreza motriz, sin el acompañamiento del pensamiento, da lugar a un ambiente que cierra la oportunidad de crecimiento, lo que será criticado constantemente por Dewey pues tal metodología la hallaba fuertemente arraigada en los centros educativos. La apuesta deweyana se dirige a la consecución de hábitos activos, aquellos que suponen pensamiento, invención e iniciativa para aplicar las capacidades a nuevas situaciones.

Esta concepción de la educación como crecimiento va a implicar dos consecuencias importantes. Ya que el crecimiento es la característica de la vida, la educación constituye una misma cosa con el crecimiento, no tiene un fin más allá de ella misma, es su propio fin. Tanto el niño como el adulto están consagrados a crecer, a desarrollarse. En este marco hay que entender la afirmación deweyana que sostiene que el criterio de valor de la educación escolar es la medida en que crea un deseo de crecimiento continuado y proporciona los medios para hacer efectivo tal deseo ${ }^{16}$. La segunda consecuencia entronca con lo que es su concepto de educación: el proceso educativo es un proceso de reorganización, reconstrucción y transformación continuas ya que ni el organismo ni el ambiente son entes estáticos, fijos. Vida es dinamismo, movimiento, cambio.

\section{II.3. Educación como reorganización de la experiencia}

Desembocamos en la definición original del pragmatista norteamericano, John Dewey, la educación como reconstrucción continua de la experiencia, donde se subraya el carácter de asignación de una significación consciente a la misma y de proactividad.

\footnotetext{
${ }^{16}$ DEWEY, J.: Democracia y Educación. op. cit. cap. 4. p. 55. 
"Alcanzamos así una definición técnica de la educación: es aquella reconstrucción o reorganización de la experiencia que da sentido a la experiencia y que aumenta la capacidad para dirigir el curso de la experiencia subsiguiente."17

Para Dewey, la infancia, la juventud y la vida adulta, se hallan todas en el mismo nivel educativo, en cuanto que en cualquier etapa se está aprendiendo, la educación no se circunscribe a determinada edad. En todo momento, lo que se ha de procurar es un enriquecimiento del significado de la experiencia, en definitiva, de la propia vida. Se trata de conseguir que, paulatinamente, se establezcan más conexiones y continuidades en las actividades que vamos desarrollando, que la información nueva no quede aislada en nuestra mente, sino que se integre en nuestra estructura cognitiva de manera sustantiva, no arbitraria, relacionándose con nuestros conocimientos anteriores ${ }^{18}$. La actividad en el ser humano comienza en una forma impulsiva, sin atender a las interacciones con otras actividades, de tal modo que podría ser calificada de "ciega". Una actividad que lleva consigo la educación o la instrucción nos hace conocer algunas de las conexiones que habían sido imperceptibles. Dewey pone un ejemplo bastante aclaratorio ${ }^{19}$ : un niño que toca una luz brillante se quema. Así conoce que cierto acto de tocar en conexión con cierto acto de visión (y viceversa) significa calor y dolor, que determinada luz significa una fuente de calor. De este modo, sus actos en relación con estas cosas adquieren más sentido, sabe mejor lo que está haciendo o lo que ocurre, puede dirigir las consecuencias en vez de dejar que sucedan sin más.

Enlazamos con el otro aspecto de una experiencia educativa, proporcionar un poder adicional de dirección o control subsiguiente. Decir que se conoce lo que ocurre, supone ser capaz de prever lo que va a suceder si se efectúan ciertas acciones, es ser capaz de anticiparse a los acontecimientos, de prepararse ante las consecuencias. Dewey distingue, al respecto, la experiencia auténticamente educativa de la actividad caprichosa y de la rutinaria. En la acción caprichosa no hay preocupación por parte del sujeto acerca de lo que acontece, evita relacionar las consecuencias del acto con el propio acto. En este sentido, Dewey se queja de que muchas veces en las instituciones escolares se establecen reglas acerca de cómo ha de ser la actuación de los alumnos en determinados campos sin que se les haga ser conscientes de la conexión entre la respuesta o resultado y el método empleado. Sería el caso del discente que comenta que sabe cómo resolver un problema pero no por qué se soluciona de ese modo.

Junto con las actividades caprichosas, Dewey sitúa la acción rutinaria o automática. Aquí podríamos emplazar el análisis antes efectuado en la concepción de la educación como adiestramiento de facultades. La rutina puede aumentar la habilidad para hacer una cosa particular, de manera que, bajo esa perspectiva, sí se hablaría de efecto educativo. Ahora bien, no conduce a nuevas percepciones de las conexiones y consecuencias, limita más que amplia el horizonte significativo. Supone un obstáculo, una traba, para actuar con esa flexibilidad que debe de caracterizar el comportamiento del ser humano y que es un rasgo que lo distingue del resto de las criaturas. El ambiente cambia por lo que nuestro modo de actuación ha de modificarse para mantener una conexión equilibrada con el entorno. Una forma aislada de actuar llega a ser desastrosa en los momentos críticos, ante los nuevos retos y desafíos que tienen lugar en nuestra vida. La "destreza", producto de esa rutina, se convierte en ineptitud.

\footnotetext{
${ }^{17}$ Ibídem. cap. 7. p. 74.

${ }^{18}$ Esta es una condición imprescindible para que se produzca lo que en nuestro días denominamos como aprendizaje significativo.

${ }^{19}$ DEWEY, J.: Democracia y Educación. op. cit. p. 74. 
En todo este análisis de la educación como reconstrucción, se observa el papel de primer orden que juega la inteligencia, entendida como método de observación, de experimentación, de razonamiento reflexivo y no como ningún órgano o facultad que nos permite adueñarnos de verdades últimas. La reconstrucción que hay que acometer, la educación como reorganización de la experiencia, no consiste sino en una aplicación contínua de esa capacidad intelectual, reflexiva, a nuestra vida que la hace enriquecerse sin pausa. No es extraño, pues, su definición de la filosofía como teoría de la educación que no es sino una práctica deliberadamente dirigida ${ }^{20}$ :

"Si estamos dispuestos a concebir la educación como el proceso de formar disposiciones fundamentales, intelectuales y emocionales respecto a la naturaleza y los hombres, la filosofía puede, incluso, definirse como la teoría general de la educación. A menos que una filosofía haya de seguir siendo simbólica - o verbal - o una satisfacción sentimental para unos pocos, o un mero dogma arbitrario, su examen de la experiencia pasada y su programa de valores tienen que influir en la conducta." ${ }^{21}$

La filosofía de la educación sería, para Dewey, una formulación explícita de los problemas de formación de hábitos mentales y morales adecuados a las dificultades de la vida social del momento. En Democracia y Educación (1916) y en Reconstrucción de la Filosofía (1920), entre otras, habla de la necesidad de una reconstrucción de la filosofía, de la educación y de los ideales que tendrían que marchar paralelamente ${ }^{22}$. Dewey observa que los avances científico-técnicos, en especial en el campo de la física, la revolución industrial y el desarrollo de la democracia han dado lugar a cambios sociales de gran magnitud y ha hecho urgente una revisión de las ideas básicas de los sistemas filosóficos tradicionales. Dichas transformaciones prácticas exigen una reconsideración, reconstrucción o reorganización de la educación:

\footnotetext{
"Tales cambios prácticos no pueden tener lugar sin exigir una reforma educativa para satisfacerlos, y sin llevar a los hombres a preguntar por las ideas e ideales que están implicados en estos cambios sociales y por las revisiones que requieren de las ideas e ideales heredados de culturas más antiguas y diferentes." 23
}

Dewey consideraba necesaria una reforma educativa, una transformación de los métodos tradicionales escolares. Había que dar respuesta al ser humano del siglo XX que sería aquel que hiciera de la democracia no sólo un régimen político sino un estilo de vida, una forma de relacionarse con la naturaleza y con sus semejantes. Dewey contaba con un instrumento de primer orden: la educación.

\section{CAPACIDAD CONTINUADA PARA EL DESARROLLO, FIN DEWEYANO DE LA EDUCACIÓN Y DE LA VIDA}

Una figura como John Dewey, fuertemente comprometida por una mejora de todo lo concerniente al mundo educativo, que no era, a su entender, sino el pilar fundamental para lograr una sociedad más libre, más humana, no podía sin duda dedicar un tiempo a reflexionar sobre un tema tan controvertido como el de los fines. No sólo en libros como Democracia y Educación (1916), sino también en artículos como "General Principles of Educational Articulation" (1929), Dewey escribe sobre cuál es y cómo ha de entenderse

\footnotetext{
${ }^{20}$ Ibídem. cap. 24. p. 278.

${ }^{21}$ Ibídem. pp. 275-276.

22 "(..) la reconstrucción no puede ser menos que la tarea de desarrollar, de formar, de producir (..) los instrumentos intelectuales que habrán de llevar de una manera progresiva la investigación hacia las realidades profunda y totalmente humanas - es decir, morales - de la situación y del panorama de nuestro tiempo." DEWEY, J.: La reconstrucción de la filosofia. Ed. Aguilar. Buenos Aires. $4^{\text {a }}$ ed. 1970. p. 51.

${ }^{23}$ DEWEY, J.: Democracia y Educación. op. cit. cap. 24. p. 278. 
el fin de la educación, reflexiones que estarán directamente conectadas con su propia concepción de educación como reconstrucción.

Para John Dewey, el proceso educativo no es sino el de la vida misma y ésta es ante todo crecimiento, desarrollo ${ }^{24}$. Dilucidar su fin, entendido éste como algo prefijado, acabado, no tiene - dirá Dewey - mucho sentido porque si algo define la vida es esa capacidad de crecer, de extenderse, de enriquecerse. La vida es puro dinamismo, transformación, contínua reorganización. Si hablamos, pues, de fin último hemos de concluir que, en el caso de la educación, será éste la vida en sí misma, un incremento de la propia vitalidad que no es más que un enriquecimiento de su significado, de las conexiones que vamos estableciendo gracias a la experiencia ${ }^{25}$. El fin de la educación, el objeto y la recompensa del aprender es así la capacidad continuada para el desarrollo ${ }^{26}$, lograr que los seres humanos posean inquietudes que les lleven a un constante afán por mejorar, con un pensamiento abierto, tolerante, liberal, con un gusto cultivado y con un bagaje de conocimientos y métodos que les permitan conseguir el tan ansiado bienestar social:

"For the ultimate aim of education is nothing other than the creation of human beings in the fulness of their capacities through the making of human beings, of men and women generous in aspiration, liberal in thought, cultivated in taste, and equipped with knowledge and competent methods, society itself is constantly remade, and with this remarking the world itself is re-created." ${ }^{27}$

\section{III.1. Caracteres del término fin: orden y anticipación de resultados}

Hemos indicado la conclusión final, el resultado al que llega John Dewey acerca de la meta última que ha de plantearse todo proceso educativo. Ahora bien, dicha conclusión es fruto de un razonamiento previo por parte de nuestro autor que es digno de mostrarse ${ }^{28}$. Se inicia con el análisis del término "fin", desde una perspectiva pragmática, haciendo alusión a sus implicaciones. Hablar de "fin" apunta a una actividad ordenada, dirigida a la terminación progresiva de un proceso. Supone anticipar un resultado. Dicha previsión trae consigo tres consecuencias: la necesidad de observar las condiciones de la situación, de cara a calcular los medios disponibles para alcanzar el fin; realizar una selección de tales medios y ordenarlos para lograr el resultado deseado con eficacia y, por último, posibilitar la elección de alternativas, permitir comparar entre varios planes de acción, con vistas a emitir juicios sobre la conveniencia de cada uno. Si examinamos cómo se relacionan estos tres puntos, si pensamos en qué es lo que hay implicado en cada uno de estos tres procesos, nos daremos cuenta fácilmente de cuál es el denominador común: la inteligencia, o, tal como la nombra frecuentemente Dewey, el espíritu ${ }^{29}$.

El espíritu (spirit) va a ser equivalente a la conciencia, la que, a diferencia del tratamiento otorgado por la mayor parte de los filósofos anteriores, no será considerada como un sustantivo sino que funcionará como adjetivo, caracterizando determinado tipo de actuaciones. Ser consciente se traduce en actuar conscientemente, en darse cuenta de lo que ocurre y observar, planear la acción. La conciencia designa la cualidad con propósito de una actividad, aquella que se dirige intencionalmente a lograr un fin

\footnotetext{
${ }^{24}$ DEWEY, J.: Definición de values educational. A Cyclopedia of Education. O.C./ M.W. 7: p. 365.

${ }^{25}$ Ibídem. p. 364.

${ }^{26}$ DEWEY, J.: Democracia y Educación. Ed. Morata. Madrid. 1995. cap. 8. p. 92.

${ }^{27}$ DEWEY, J.: "Philosophy and Education". O.C./ L.W. 5: p. 297.

${ }^{28}$ Tomamos como obra fundamental para este análisis Democracia y Educación (1916).

${ }^{29}$ DEWEY, J.: Democracia y Educación. op. cit. cap. 8. p. 94 
específico $^{30}$. Conciencia, inteligencia, espíritu, son así tres términos estrechamente unidos.

\section{III.2. Criterios de los buenos fines}

A la hora de decidir sobre los fines que se establezcan para cualquier ámbito, es conveniente partir de ciertos criterios. John Dewey establece tres criterios generales y luego muestra sus implicaciones educativas ${ }^{31}$. El primero de ellos, apunta al hecho de que las metas que se formulen han de basarse en las condiciones existentes, en la realidad que se está dando, en los recursos y dificultades de la situación. En este sentido, critica aquellas teorías que sitúan los fines fuera de las actividades del sujeto implicado, extraños a la estructura concreta de la situación, procedentes de alguna fuente exterior. Subraya Dewey que éstos originan una limitación de nuestra inteligencia: se nos dan ya preparados, impuestos por una autoridad externa, distinta a la capacidad racional del individuo. Al sujeto no le queda sino efectuar una elección mecánica de los medios para alcanzar tal fin. Centrándonos en el terreno educativo, este criterio da lugar a que los fines educativos deben fundarse en las actividades y necesidades intrínsecas incluyendo los instintos y los hábitos - del individuo determinado que ha de educarse, tienen que partir de sus capacidades, del nivel evolutivo en que se encuentra. Es la única forma de que sean factibles y que den lugar a ese fin último de fomentar una capacidad continuada de desarrollo.

En segundo lugar, y directamente conectado con el anterior, Dewey apunta a la necesidad de flexibilidad en el establecimiento de los fines, no pueden ser rígidamente fijados de antemano. Hay que verlos como bosquejos, como un boceto de lo que podrá ser la obra final. Ordinariamente, en las situaciones complejas, a medida que se desarrolla la acción, se van observando una serie de circunstancias que en un primer momento pasaron inadvertidas. Ello exige la necesidad de una revisión constante, la posibilidad de una modificación tanto de la meta como de los recursos planteados primeramente para conseguirla. El fin, tanto, ha de permitir esos cambios, tiene que ser flexible, hasta el punto que Dewey señala que la medida de su valor se encuentra en el hecho de que podamos emplearlo para cambiar las condiciones, como método para tratarlas de forma que se efectúen en ellas las alteraciones deseadas ${ }^{32}$. En el terreno educativo, la aplicación de estas ideas da lugar a que las finalidades siempre han de partir del estado actual de la experiencia de los alumnos y deben de dar pié a la organización de un plan para alcanzar tales metas. Ahora bien, manteniendo ese proyecto constantemente a la vista, deben ser flexibles para admitir su modificación cuando las condiciones lo exijan. Se van desarrollando contínuamente a medida que se prueban en la acción, significado al que alude Dewey cuando dice que los fines educativos son experimentales.

Un tercer criterio señalado por John Dewey apunta al hecho de que el fin represente siempre una liberación de actividades, sugiera la conclusión de un proceso. El fin no será así la consecución de un objeto sino hacer algo con él, por ejemplo, dirá Dewey, en la caza de un conejo, el fin no es el conejo como tal, sino comerlo, mostrarlo como prueba de destreza, etc ${ }^{33}$. El objeto es una fase del fin activo: continuar la actividad con

\footnotetext{
${ }^{30}$ Ibídem. p. 95.

${ }^{31}$ Ibídem. pp.95-97. Dewey indica que no hay nada peculiar en los fines educativos: son iguales que los de cualquier ocupación dirigida. Compara el trabajo del educador con el del agricultor.

${ }^{32}$ Ibídem. p. 96.

${ }^{33}$ Ibídem. p. 96. 
éxito, que es a lo que se refiere Dewey cuando habla de "actividad liberadora". A este tipo de fin, se opone aquel impuesto desde fuera de la actividad, que se caracterizará por ser fijo y que es algo que se ha de alcanzar y poseer. Ello, para Dewey, va en detrimento de la actividad que deja de ser significativa o importante por sí misma. Su papel se reduce a ser un medio para hacer algo. Dewey posee planteamientos bien distintos. La idea externa de fin conduce -señala el filósofo - a una separación de los medios respecto del fin - uno de los clásicos dualismos -. El "buen" fin, aquel que se desarrolla dentro de una actividad como plan para su dirección es siempre, a la vez, fin y medio, es decir, es meta presente pero tendrá que servir, con posterioridad, de instrumento para una meta "superior". El aprender a sumar, por ejemplo, en determinada etapa de nuestra vida constituye un objetivo educativo; una vez alcanzado, es el medio para otros logros como dominar la multiplicación, y, éste, más tarde, será instrumento para realizar divisiones 0 , después, raíces cuadradas:

"Todo medio es un fin temporal hasta que lo hayamos alcanzado. Todo fin llega a ser un medio de llevar más allá la actividad tan pronto se ha alcanzado. Lo llamamos fin cuando señala la dirección futura de la actividad a la que estamos dedicados; medio, cuando indica la dirección presente." ${ }^{34}$

El fin externamente impuesto no sólo lo refiere Dewey al caso del alumno respecto al profesor sino que lo ve en un conjunto más amplio. Es el docente quien en primer lugar encuentra coartada su capacidad de elegir, su uso de la inteligencia. Ha de cumplir unas finalidades que les vienen dadas por autoridades superiores llámese inspección o plan de estudios prescrito. Su papel se reduce a implementar una decisión ajena, actúa como un mero ejecutor mas no se le reconoce su rol en la toma de decisiones. Esta desconfianza respecto a la experiencia del maestro, a su "profesionalidad", a su capacidad de valorar acerca de lo más correcto en el plano educativo, John Dewey piensa que se refleja entonces en la falta de confianza referida a la respuesta de los alumnos quienes "reciben sus fines a través de una doble o triple imposición externa, y se hallan constantemente confusos por el conflicto entre los fines que son naturales a su propia experiencia en el momento y aquello a lo que se les enseña a someterse." ${ }^{35}$

El "buen" fin educativo debe ser sugerir el ambiente necesitado para liberar $y$ organizar las capacidades del educando. Asimismo, el docente ha de estar en guardia contra los fines que se alegan como generales y últimos. Para Dewey, el que la educación sea un fin en sí misma, es decir, que sea siempre su propia recompensa, supone que ningún estudio o disciplina son educativos si no poseen valor propio inmediato. Fines generales -dirá John Dewey- son los que nos hacen ver todas las conexiones que hay en una situación, tener en cuenta más fuerzas interactivas y descubrir un gran número de medios.

Como conclusión, el fin último de la educación es el enriquecimiento del ser humano, es asegurar la continuidad de la vida, proporcionar los medios para mantener un proceso vital que incluye un aumento constante del significado de las experiencias. Proceso de vida y proceso educativo se identifican en el caso del sujeto humano, y éste es inseparable de un ambiente que no es sólo físico sino que es también social. El fin educativo por excelencia es la vida misma, no es externo a ella, no hay separación educación-vida y la dicotomía individuo-sociedad no tiene sentido cuando se habla de bienestar de la comunidad.

\footnotetext{
${ }^{34}$ Ibídem. pp. 96-97.

${ }^{35}$ Ibídem. p. 99. 


\section{VIGENCIA ACTUAL DEL PENSAMIENTO DEWEYANO: LA APUESTA POR EL CIUDADANO DEMOCRÁTICO, FIN DE LA EDUCACIÓN DEL SIGLO XXI}

El pensamiento educativo de John Dewey posee en la actualidad plena vigencia. En los albores del siglo XXI, su mirada crítica, sus reflexiones sobre el mundo educativo siguen conservando su fuerza vital, su poder de incitarnos al cambio de una situación que no nos satisface del todo, aquella en que se halla la educación.

Indicamos las que nos parecen las principales aportaciones deweyanas a la realidad educativa de hoy en día en el campo de la Filosofía-Teoría de la Educación. La primera parada en estas reflexiones finales debe ser en el concepto de educación como reconstrucción continua de la experiencia. En el mundo de hoy, poco o nada queda de la idea de una realidad donde el ser humano no intervenga en su creación ${ }^{36}$. La corriente constructivista se ha ido imponiendo a medida que ha ido transcurriendo el siglo XX y ella enfatiza el papel de los sujetos interaccionando con un medio al que asigna significados, dando sentido a la realidad ${ }^{37}$. La educación es vida, es desarrollo, es crecimiento, en palabras del filósofo pragmatista. En suma, es un cúmulo de experiencias que intentan enriquecernos, gracias a un aumento del significado de cada nueva situación vital, enriquecimiento producido mientras la experiencia pueda ser estimada como educativa.

Esta manera de concebir la educación es ampliamente aceptada en la actualidad, en una huida del adiestramiento o del adoctrinamiento. Se busca capacitar al ser humano para afrontar las múltiples experiencias que le depara su devenir en el mundo, capacitación que le lleve a la comprensión del significado de cada hecho en que se vea envuelto y que le permita intervenir en esa situación, actuar. Ahora bien, en esa actuación un instrumento clave va a ser la inteligencia, la razón, esa poderosa fuerza que nos permite observar cuidadosamente todos los factores implicados, seleccionar los recursos que nos posibiliten la solución del problema y juzgar la estrategia más oportuna $^{38}$. Es la inteligencia que está al servicio de una determinada ética: aquella que busca el bienestar social sin descuidar la autorrealización del individuo, pues ésta pasa por la relación intersubjetiva ${ }^{39}$. La inteligencia nos ayuda a controlar los medios para la realización de fines. En el fin, en la respuesta a la pregunta del para qué es donde también ha de concentrarse toda la potencia de la racionalidad humana.

El Informe Delors, a finales del siglo XX, no hace sino subrayarnos este enfoque educativo. Expone que el principal problema en el siglo XXI no será tanto preparar a los niños para vivir en una sociedad determinada como el de dotar a los individuos de fuerzas y puntos de referencia intelectuales permanentes que les permitan comprender el mundo que les rodea y comportarse de manera responsable y justa. La función

\footnotetext{
36 "Para Dewey, como para el postmodernismo, nada hay externo a la experiencia, no hay "esencia" de la naturaleza humana. En cambio, hay seres humanos que configuran y son configurados por su historia, mientras hacen su camino al andar a través de un mundo incierto, atravesado por contingencias, mundo siempre incompleto y siempre haciéndose." CARR, W.: "Educación y democracia: Ante el desafío postmoderno". En AAVV: Volver a pensar la educación. vol. I. Ed. Morata / Paideia. Madrid, 1995. p. 109.

${ }^{37}$ Sobre el carácter constructivista del pensamiento deweyano se pueden consultar los artículos: GARRISON, J.: "Deweyan Pragmatism and the Epistemology of Comtemporary Social Constructivism", American Educational Research Journal, 34, $\mathrm{n}^{\circ} 4$, 1996, pp. 716-740; GARRISON, J.: "A Deweyan Theory of Democratic listening". Educational Theory. vol. 46, n 4. Fall 1996. pp. 429-452; BERNAN, S., WANDERMAN, J., BRIONES, E. y KURTINES, W.: "Education for Democracy: A co-constructivist perspective". Teoría de la Educación. vol. V. Eds. Universidad de Salamanca. 1993. pp. 87-96.

${ }^{38}$ DEWEY, J.: "The Need for Orientation". Problems of Men. Ed. Philosophical Library, Inc. New York, 1946. p. 90.

${ }^{39}$ Recordemos que, para Dewey, la libertad es una liberación y realización de las potencias personales que tienen lugar solamente en una asociación rica y múltiple con los otros. DEWEY, J.: El Público y sus problemas. Colección "Hombres y Problemas". Ed. Agora. Buenos Aires. 1958. p. 123. 
esencial de la educación - y aquí vemos plena coincidencia con De33wey - es conferir a todos los seres humanos la libertad de pensamiento, de juicio, de sentimientos y de imaginación que éstos necesitan para alcanzar la plenitud de sus capacidades y seguir siendo artífices, en la medida de lo posible de su destino ${ }^{40}$.

Se comprende así la insistencia deweyana en que el fin de la educación es la educación misma, puesto que el fin será siempre la capacidad continuada de crecimiento, de desarrollo. Se trata de la idea actualmente aceptada de educación permanente, de educación a lo largo de toda la vida. No hay ninguna etapa dentro del ciclo vital humano en la que se frene la posibilidad de enriquecernos, de incorporar a nuestro ser conceptos, habilidades, valores nuevos. Constantemente hemos de enfrentarnos a ese reto del que ninguno podemos escapar que es la vida y por lo tanto cada experiencia se abre como posibilidad de aprendizaje. Sin duda, Dewey acierta en el criterio por excelencia de la enseñanza de calidad: aquella que fomenta en el discente el deseo de aprender, de continuar ampliando su horizonte como ser humano, de adquirir nuevos conocimientos, aunque no hemos de descuidar su segunda condición, proporcionar los recursos para lograrlo. Es ese "aprender a aprender" -aprender para conocer $^{41}$-, reflejo de lo que el educador ha de buscar como meta más alta: la plena autonomía del educando en su proceso de aprendizaje, sin necesitar el continuo andamiaje del docente.

Ahora que en el mundo occidental parece prácticamente superado el reto de la escolaridad obligatoria, se habla con mayor frecuencia de la calidad de la enseñanza. Ya hay enseñanza para todos: el nuevo desafío consiste en procurar que sea buena. Muchos son los indicadores que se establecen con el fin de delimitar si realmente se consigue o no dicha calidad, pero pensamos que esos dos criterios básicos deberían de servir como puntos de referencia. Ellos estarán rodeados de factores como la cualificación y formación del profesorado, la programación docente, la orientación educativa y profesional, la innovación y la investigación educativa o la inspección, mas siempre serán el Norte al que debe apuntar la aguja de nuestra brújula.

La calidad de la enseñanza va a ser un apoyo de primer orden al objetivo último de calidad de vida, cuestión que enlaza de modo directo con una de las preocupaciones más acuciantes para John Dewey, el de la consecución de la auténtica democracia, basada, sin duda, en una determinada ética. Democracia, en opinión del filósofo norteamericano, significa el esfuerzo para conducir los asuntos sociales sobre una base ética. Está convencido de que cualquier sociedad preocupada en dar a sus miembros la más alta calidad de experiencia, material y culturalmente, procurará organizar sus asuntos por vías democráticas ${ }^{42}$.

La democracia, para el pragmatista, es mucho más que un régimen de gobierno: es un estilo de vida, es una forma de afrontar nuestra existencia. Nadie nace demócrata: hay que aprender a ser demócrata. En esta concepción democrática es donde crece la filosofía de la educación deweyana y es a la que se aspira en nuestros días. Hay que incorporar a nuestra personalidad, a nuestro carácter, las características del ser humano democrático, de la persona realmente humana. No es difícil adivinar el papel esencial

\footnotetext{
${ }^{40}$ COMISION INTERNACIONAL SOBRE LA EDUCACION EN EL SIGLO XXI: La educación encierra un tesoro. Informe Delors. Ed. Santillana-UNESCO. Madrid, 1996. p. 107.

${ }^{41}$ En el Informe Delors se señala que el "aprender para conocer", para aprehender el significado de la realidad, para adaptarnos activamente al mundo que nos rodea, supone en primer término "aprender a aprender", ejercitando la atención, la memoria y el pensamiento. Ibídem. p. 98.

${ }^{42}$ CHILDS, J.L.: "Educational Philosophy of Dewey". The Philosophy of John Dewey. op. cit. p. 441. 
que juega la educación, máxima responsable del cumplimiento de esa meta, de ese ideal irrenunciable ${ }^{43}$. Ella será la encargada de ofrecer tanto los conocimientos necesarios para esa participación real que supone una democracia no exclusivamente formal, una información de nuestros derechos y deberes, de las funciones de las diferentes instituciones políticas y sociales que el ser humano ha creado para el pleno cumplimiento del Estado democrático, como las habilidades exigidas para desarrollar ese estilo de vida que hace del hombre dueño de su destino y, por supuesto, unos valores básicos que apoyen dichos comportamientos.

El tema de los valores creemos que es de una importancia capital en el momento actual, recién estrenado el tercer milenio. El siglo XX nos ha legado la herencia peligrosa del relativismo moral "absoluto" - valga la paradoja -, de la cultura del "todo vale", de la ausencia de referentes eternos en una patente desvirtuación del loable pluralismo ético $^{44}$. Nosotros, como Dewey y como otros intelectuales contemporáneos preocupados por la instauración de la democracia real en la sociedad - sirvan como ejemplos de filósofos españoles José Luis López Aranguren, Victoria Camps y Fernando Savater - no compartimos este "relativismo moral absoluto". Pensamos que hay un núcleo básico irrenunciable. La educación, que debe dirigirse al pleno desarrollo de la personalidad de sus destinatarios, ha de contar con un marco comúnmente aceptado, a modo de eje de referencia, que todos han de respetar y frente al cual siquiera cabe la tolerancia ${ }^{45}$. La dignidad de todo ser humano y el respeto de los derechos que le son inherentes constituye dicho núcleo, tal como ha ido constitucionalizándose tras la Segunda Guerra Mundial. La base son valores como libertad, justicia, paz, solidaridad ${ }^{46}$.

Se puede aceptar el relativismo, pero marcando un límite. La ética tiende a la universalidad de los valores - recuérdese el imperativo categórico kantiano - y lo que nos exige la ética es que aquello que defendemos como algo que "debe ser" es porque "queremos que sea en todas partes". Un principio ético es un principio que no vale únicamente "aquí y ahora" sino que aspiramos a que sea aceptado por todos, postulamos una exigencia de universalidad. El hecho, además, de que actualmente parezca existir un consenso acerca de cuáles son esos valores esenciales, aquellos que están en la base de los derechos humanos, no nos debe dejar satisfechos. Como señala Victoria Camps $^{47}$, la dificultad no radica en hallar los valores o principios, sino los criterios que dirijan la acción de las personas: lo difícil es saber qué significa ser tolerantes hoy, con quienes hay que ser tolerantes; qué supone ser solidarios, quienes

\footnotetext{
${ }^{43}$ Citemos por ejemplo a uno de los principales representantes de las pedagogías críticas contemporáneas como es Giroux quien afirma en Los profesores como intelectuales. Hacia una pedagogía crítica del aprendizaje (1990): "Las escuelas se han de ver como esferas públicas democráticas dedicadas a potenciar a la persona y a la sociedad. Lugares públicos donde los estudiantes aprenden los conocimientos y las habilidades necesarios para vivir en una auténtica democracia. Formas de investigación crítica que ennoblecen el diálogo significativo y la iniciativa humana. El aprendizaje del discurso de la asociación pública y la responsabilidad social". Las pedagogías críticas son una consecuencia del proyecto político de la Modernidad y la Ilustración, proyecto que también compartió John Dewey. En tanto que proyecto político, la educación ha de ser emancipadora, es decir, ha de liberar no sólo las conciencias del yugo de lo acientífico e irracional, sino también deberá construir un proceso de transformación, de renovación, de reconstrucción de lo social. MARTIN BONAFE, J.: "Poder y conciencia". Cuadernos de Pedagogía. nº 253, diciembre, 1996p. 79.
}

\footnotetext{
${ }^{45} \mathrm{M}$. Trimarchi defiende la necesidad de situar límites a la tolerancia, exactamente los representados por el respeto a los derechos humanos; de otro modo, la tolerancia podría justificar el atentado a la propia dignidad. TRIMARCHI, M.: "Il concetto di "tolleranza" contraddice il rispetto dei diritti umani". Cultura e Natura. n 3. Roma. 1994. p. 5.
}

La conexión entre estos valores es subrayada en nuestros días. Sirva como ejemplo el siguiente fragmento de Pérez Serrano: "Se puede subrayar,...), que la tolerancia es la virtud, o la actitud, que mueve al respeto. Incluye apertura, acogida, diálogo, paz, comprensión y libertad. La libertad es ciertamente condición para la tolerancia. Así pues, libertad, tolerancia, pluralismo y democracia no son términos idénticos, pero sí inseparables." PEREZ SERRANO, G.: Cómo educar para la democracia. Ed. Popular. Madrid, 1997. p. 47.

${ }^{47}$ CAMPS, V.: "La educación en valores ante el fin de siglo". En AAVV: Educación y valores. AIDEX. Plasencia. 1996. p. 41. 
merecen más solidaridad. Ser autónomo consiste en poseer criterios para decidir sobre esas cuestiones ${ }^{48}$.

Se entiende el papel capital que concede Dewey a la Educación Moral y que en nuestro momento actual se está reivindicando, una educación que huye de cualquier tipo de adoctrinamiento, una educación que debería de impregnar todo el currículum, toda experiencia educativa. Dewey nunca habla de la Etica como una asignatura independiente: ella está presente en toda actividad social, en toda situación humana que tenga lugar en la escuela; toda educación es educación moral en cuanto a que ha de capacitar a los individuos para participar más activa y significativamente en la vida social. Virtud, para Dewey, es sinónimo de capacidad, de instrumento para conseguir bienes y realizaciones satisfactorias. La capacidad de pensamiento crítico, reflexivo alcanza así un valor esencial. Su consecución debe ser uno de los objetivos fundamentales del sistema educativo, junto con el de la adquisición de las habilidades necesarias para establecer una coherencia entre el juicio y la acción moral.

Podríamos preguntarnos acerca del por qué de ese énfasis en el presente sobre la educación moral en un momento en que en la mayoría de los países occidentales contamos con un sistema democrático. La respuesta está en la toma de conciencia de que la conquista de la democracia como régimen de gobierno no implica necesariamente el advenimiento de la democracia como estilo de vida. Sin esta última acepción de la democracia, el sistema democrático como forma de gobierno se convierte en mera ficción, en una representación teatral que causa la apatía de gran parte de los ciudadanos que no se sienten realmente representados, que desconfían de aquellos que ocupan los puestos de gobierno. La democracia real ha de entenderse como una comunidad de personas que colabora en un bien común y nos preguntamos: ¿existe ese sentimiento de comunidad?, ¿se vive esa búsqueda compartida del bienestar de todos?. Sería cínico contestar afirmativamente, experimentando cotidianamente un ambiente donde reina el más cruel individualismo y una desafección por los problemas comunes, dos principales tendencias de la sociedad actual, fuertemente incentivadas por un régimen económico capitalista, neoliberal, que fomenta la iniciativa individual, el incremento injustificado de necesidades y la desigual distribución de las mismas y no premia la aspiración a la justicia y la equidad social ${ }^{49}$. Sin duda, no podemos estar tranquilos con la realización actual de la democracia en los países que, a sí mismos, se califican de "democráticos".

Juan Delval, en Los fines de la educación (1993), manifiesta claramente esa inquietud por prestar atención al terreno educativo para hacer la democracia efectiva, sin olvidar el apoyo en otros campos. Es a partir de este ámbito desde donde se puede lograr fomentar especialmente la capacidad de pensar por sí mismo, con independencia, evitando todo dogmatismo ${ }^{50}$. Muchos son los factores que tendrían que ser cambiados dentro de la misma comunidad educativa. Es interesante la propuesta de López Sánchez

\footnotetext{
${ }^{49}$ Esta opinión personal se puede ver también en: CAMPS, V.: "Educar para la democracia". Perspectivas. vol. XXVII. $\mathrm{n}^{\circ} 4$, diciembre 1997, pp. 529-530 y ARANGUREN GONZALO, L.A. y SAEZ ORTEGA, P.: De la tolerancia a la interculturalidad. Un proceso educativo en torno a la diferencia. op. cit. p. 30.

50 "[la democracia] sólo es posible cuando hay una igualdad de opciones y de oportunidades real y no meramente formal. Conseguir esto supone, entre otras cosas, (además de abundancia e igualdad económica) educación, acceso a la cultura, y en particular, capacidad de pensar por sí mismo, con independencia, sin ser esclavo de la autoridad y la propaganda. La escuela tendría que educar para la libertad y para la responsabilidad y no para la sumisión mientras que en la situación actual lo que se hace es preparar a los futuros ciudadanos para seguir siendo menores de edad cuando lleguen a adultos." DELVAL, J.: Los fines de la educación. Ed. Siglo XXI. Madrid, 2a ed. 1993. p. 34. 
que apunta a los siguientes ejes en torno a los cuales se tendría que organizar el centro escolar: participación frente a pasividad, consenso frente a imposición, disciplina inductiva frente a disciplina autoritaria, resolución de conflictos de forma pacífica y justa frente a violencia o arbitrariedad, sistemas de evaluación que sean percibidos como eficaces para el proceso de enseñanza y como justos, en cuanto a sancionadores, los profesores como modelos aceptables y como educadores frente al profesor como técnico, la diversidad frente a uniformidad o racismo.

Esta propuesta conecta directamente con el énfasis deweyano en el cuidado del ambiente que rodea al sujeto, a partir del cual éste va configurando su personalidad, su manera de enfrentarse al mundo, su estilo de vida ${ }^{51}$ y en la implicación que debe existir por parte de toda la sociedad para que éste desarrolle en el individuo las "virtudes" democráticas. La pregunta clave es "¿Qué tipo de persona deseamos?" y la respuesta deweyana es una apuesta humanista por la consecución del hombre realmente libre, con una libertad que llevaría incluídos tres elementos: la eficiencia en la acción, como habilidad para realizar planes, superando los obstáculos que los dificulten; la capacidad para modificar proyectos en virtud de las circunstancias cambiantes, es decir, la flexibilidad; y un equipamiento mental, una capacidad de reflexión a partir de un conocimiento suficiente de los hechos que nos permita emplearlo para cumplir nuestros objetivos. La inteligencia es la clave de la libertad de acción. Dewey indica que la probabilidad de proceder con éxito está en relación directa con el grado en que el individuo haya estudiado las condiciones de la situación e ideado un plan que, contando con ellas, le lleve a satisfacer su meta. Se trata de una propuesta análoga a la que defienden en nuestros días intelectuales como Fernando Savater quienes abogan por el fomento de la racionalidad como principal instrumento emancipador del ser humano. ${ }^{52}$

La apuesta por el humanismo se traduce en un cultivo del pensamiento reflexivo, de la capacidad para comprender los hechos, los fenómenos sociales, situándolos en amplios contextos, para saber analizar los factores que inciden sobre ellos. Sólo así el ser humano estará preparado para actuar, para intervenir en la realidad, para progresar. Cultura, para Dewey, no es simple erudición, mera acumulación de información: el hombre culto es aquel que es capaz de comprenderla. La información, aunque necesaria, sin comprensión está muerta; no permite actuar, modificar el ambiente, por lo que se aleja de la esencia del ser humano que es la acción. Es la misma preocupación que reflejaba la UNESCO, en un informe publicado a finales del siglo $X X$, en el que se liga la posibilidad de comprensión de la información a la capacitación para la ciudadanía. ${ }^{53}$

\footnotetext{
51 "For a Deweyan, the curriculum, teaching methods, the organization of time and physical space, would all reflect a concern for character development". RICE, S.: "Dewey's conception of "virtue" and its implications for Moral Education". Educational Theory. vol. 46. $\mathrm{n}^{\circ}$ 3. Summer 1996. p. 282.

${ }^{52}$ SAVATER, F.: El valor de educar. Ed. Ariel. Barcelona. $8^{\text {a }}$ ed. 1997, p. 134. Cita de PASSMORE, J.: Filosofia de la enseñanza. Ed. Fondo de Cultura Económica. México.
}

\footnotetext{
"Pero no sólo el acceso a la información nos interesa. La posibilidad de participación está del lado de quien puede "hacer uso" de la información, no sólo porque la conoce, sino, y fundamentalmente, porque la ha analizado, evaluado y elaborado estrategias de acción y decisión a partir de ella. La tarea del ciudadano no consiste ya en delegar su poder, sino en ejercerlo en todos los niveles de la sociedad y en todas las etapas de la vida. Cuando las autoridades de los Estados tienen que tratar con mayorías de ciudadanos verdaderamente adultas o con minorías poderosas y activas no pueden entusiasmar a las personas a las que gobiernan con cualquier proyecto perjudicial que puedan haber ideado, como hacen cuando tratan con poblaciones maleables, "mal informadas", a las que se engaña contra sus propios intereses." ${ }^{5353}$ "Pero no sólo el acceso a la información nos interesa. La posibilidad de participación está del lado de quien puede "hacer uso" de la información, no sólo porque la conoce, sino, y fundamentalmente, porque la ha analizado, evaluado y elaborado estrategias de acción y decisión a partir de ella. La tarea del ciudadano no consiste ya en delegar su poder, sino en ejercerlo en todos los niveles de la sociedad y en todas las etapas de la vida. Cuando las autoridades de los Estados tienen que tratar con mayorías de ciudadanos verdaderamente adultas o con minorías poderosas y activas no pueden entusiasmar a las personas a las que gobiernan con cualquier proyecto perjudicial que puedan haber ideado, como hacen cuando tratan con poblaciones maleables, Digitalizado por RED ACADEMICA
} 
Se llega así a otra pregunta clave del currículum. Aclarado el interrogante primario del para qué, descendemos a otro referido al contenido, al qué enseñar. El criterio defendido por el filósofo pragmatista para seleccionar la materia de estudio es el valor social, es decir, la contribución que pueda hacer a la mejora de la vida del individuo en su estar en el mundo y a la sociedad donde éste habita ${ }^{54}$.

Si educar se entiende en un sentido amplio, como enseñar a vivir, se observa claramente la racionalidad del criterio deweyano. La escuela no puede separarse de la vida, no debe alejarse del universo en el que se desarrolla habitualmente el educando, del mundo que le ha tocado vivir y ese mundo es un mundo social, está formado por personas que forman parte de una determinada cultura. Era la divisa de la Escuela Nueva: Educar desde y para la vida. Aprendemos para asegurar nuestra supervivencia y el ser humano va más allá: no se satisface con vivir sino aspira a tener la mejor calidad de vida posible. Ese bienestar es buscado por Dewey a nivel individual y social, pues ambos deben estar en armonía. Los contenidos de la educación han de estar en la línea que permita alcanzarlo y ello se logra aplicando el criterio social a la hora de seleccionarlos.

Trasladando esta reflexión a nuestros días, preguntémonos por los contenidos de la educación: ¿qué materias son las que forman el currículum de la enseñanza obligatoria?, ¿qué criterios son los que se han utilizado para seleccionarlas?, ¿poseen un valor social?, y los contenidos que sí están presentes en el currículum oficial, ¿cubren todas las dimensiones del ser humano de modo que se pueda llegar a ese desarrollo integral?. Quizás la clave está, como comenta Delval, no en el qué enseñar, sino ante todo en el cómo se enseñan esas materias ${ }^{55}$. De hecho, Dewey no descartaba las disciplinas que habitualmente se impartían en las instituciones escolares: su originalidad radicaba en el cómo se le presentaban al alumnado ${ }^{56}$. Realmente se intentaba que éste sintiese su valor social, su significatividad en sus vidas, su aplicación a la práctica cotidiana, la funcionalidad de lo aprendido. Éste es el inmenso valor del papel de las "ocupaciones", de esas formas de actividad donde el niño reproducía alguna clase de trabajo relacionada con la vida social: cocinando o trabajando la madera aprendía química, física, matemáticas, ciencias sociales,..., todo, claro está, con una planificación cuidadosa del profesorado.

Dewey incluye en el contenido educativo, las actitudes, a las que concede una máxima importancia. La actitud por excelencia que pretende cultivar es la actitud reflexiva, la investigadora, la científica, aquella asociada al método experimental ${ }^{57}$ donde la inteligencia juega un papel de primer orden. Es la actitud crítica que conlleva formular claramente los problemas, plantear hipótesis, varias alternativas de solución y elegir la más adecuada, una vez analizados los pro y los contra de cada una. Es la actitud de la persona "humana", del sujeto responsable cuya libertad va unida a procurar el bienestar

\footnotetext{
"mal informadas", a las que se engaña contra sus propios intereses "Citado por MORDUCHOWICZ, R.: "La Educación para los Medios es una Educación para la Democracia". Comunicar, 13, 1999. p. 118.

54 "La educación no es un medio para vivir, sino que es idéntica a la operación de vivir una vida que es fructífera e inherentemente significativa, el único valor último que puede establecerse es (..) el proceso mismo de vivir. Y éste no es un fin para el cual son medios subordinados los estudios y actividades; es el todo del cual ellos son partes integrantes." DEWEY, J.: Democracia y Educación. Ed. Morata. Madrid. 1995. pp. 205-206.

${ }^{55}$ DELVAL, J.: "La necesidad de un nuevo humanismo". Los fines de la educación.op. cit. pp. 80-81.

56 WESTBROOK, R.B.: "John Dewey (1859-1952)". Perspectivas: Grandes educadores (Número extraordinario en dos volúmenes), vol.I, p. 298.

${ }^{57}$ Dentro de la filosofía deweyana, el método experimental se convierte así en un método para pensar y ser y no sólo queda reducido a un método didáctico. La esencia del método científico que Dewey defiende es la de un modo de proceder que nos ayuda a alcanzar los hechos "ciertos", la manera socialmente adecuada de proceder, descartando el error, eliminando prejuicios, abriendo nuestra mente a nuevas ideas,etc.
} 
individual y social. Es la actitud que lleva consigo una mentalidad abierta, un querer actuar con rectitud, ofreciendo buenas razones, una preocupación por situar cada suceso en un contexto más amplio que dé cuenta de los factores que en él inciden.

Pero estas actitudes vistas como contenido de la educación no pueden ser obtenidas sin la puesta en práctica de determinados métodos educativos. Es aquí donde la pregunta acerca del qué enseñar enlaza con la del cómo enseñar, con la didáctica y organización escolar. En este cómo está la clave de la enseñanza humanista para filósofos como Fernando Savater ${ }^{58}$ Se trata de propiciar el ambiente que se estime más adecuado para lograr que realmente interioricemos ese espíritu crítico, reflexivo, que nos permita esa adaptación activa al mundo que nos ha tocado vivir, que nos convierta en ciudadanos y no en súbditos, que nos transforme en agentes y no en meros receptores de los cambios sociales.

El método del docente ha de seguir, pues, en sus principios, las líneas de la actitud reflexiva. Habrá que darle una gran importancia a la información, porque para poder decidir acerca de cuál es la alternativa mejor para resolver un problema, para dar razones pertinentes que justifiquen nuestras elecciones, es necesario primeramente un conocimiento auténtico de los temas implicados. La actitud del profesor será la de incitar a que los propios discentes sepan buscar esa información y que no se conformen con acudir a una única fuente de datos. Será hacerles ver que la manera de presentar la información en las distintas fuentes está respondiendo a unos intereses, a una intencionalidad por parte del emisor. El propio docente ha de demostrar en clase esa actitud de huida del pensamiento dogmático, ese interés por contar con la información necesaria para adoptar decisiones racionales:

"El educador no sólo debe conocer unas técnicas, sino que ha de transmitir unos conocimientos y no sólo lo que se entiende por unos conocimientos básicos, sino unos conocimientos que hagan que el individuo vaya él mismo produciendo una capacidad crítica, una capacidad reflexiva con respecto a la sociedad." 59

Se sobreentiende que no se defiende en ningún momento una acumulación de información sin comprensión. No existe educación si no se da una captación del sentido, del significado de las experiencias, a lo que hace referencia toda la corriente actual de la psicología cognitiva con el término aprendizaje significativo. Es la comprensión de los fenómenos el paso previo para permitir una actuación sobre ellos.

Dentro del método del docente, habrá que estimular la actitud interrogante por parte del alumnado, la capacidad de preguntar, necesaria para conocer, que tanto valoraba Sócrates. El reconocimiento de la propia ignorancia es el primer paso para la búsqueda del saber. Con las preguntas, el discente aclara sus dudas, satisface su curiosidad y muestra al profesor qué áreas son las que despiertan su interés. Labor del docente será, después, discriminar las preguntas relevantes de las que no lo son, ofrecer argumentos que justifiquen su contestación, etc. Si queremos que el alumno actúe racionalmente, es decir, que base su actuación en razones pertinentes, debemos, como educadores,

\footnotetext{
58 "Según se dice, las facultades que el humanismo pretende desarrollar son la capacidad crítica de análisis, la curiosidad que no respeta dogmas ni ocultamientos, el sentido de razonamiento lógico, la sensibilidad para apreciar las más altas realizaciones del espíritu humano, la visión de conjunto ante el panorama del saber, etc. Francamente, no conozco ningún argumento serio para probar que el estudio del latín y el griego favorecen más estas deseables cualidades que el de las matemáticas o la química.(.). La virtud humanista y formadora de las asignaturas que se enseñan no estriba en su contenido intrínseco, fuera del tiempo y del espacio, sino en la concreta manera de impartirlas, aquí y ahora. No es cuestión del qué, sino del cómo." SAVATER, F.: El valor de educar. op. cit. pp. 116 y 119.

${ }^{59}$ CAMPS, V.: "La educación en valores ante el fin de siglo". En AAVV.: Educación y valores: Educación para el Desarrollo Personal y Social en la Infancia y Adolescencia. Ed. AIDEX. Plasencia, 1996. p. 44. 
comportarnos nosotros mismos como personas racionales. Este sería uno de los principales consejos de John Dewey hacia los enseñantes que, aún pareciendo de sentido común, se olvida muchas veces en las aulas.

Estas orientaciones acerca del método que hay que practicar en las instituciones educativas, nos parecen muy acertadas y pensamos que deberían de tenerse en consideración por el profesorado en la actualidad. Como Dewey, estamos en contra de ofrecer recetas, un catálogo de instrucciones, una secuenciación del currículum cerrada, ignorando el carácter abierto de cualquier situación educativa. Nos parece más correcto indicar una serie de principios generales: ser conscientes de cuáles son nuestras metas generales, los objetivos hacia los que tenemos que dirigir nuestros esfuerzos y buscar, a partir de ahí, una coherencia en los planteamientos de las actividades en el aula con los mismos.

\section{REFLEXIONES FINALES}

En este mundo de ritmo vertiginoso en el que vivimos, corremos el peligro de olvidar dirigir nuestra atención a ciertas preguntas fundamentales, aquellas que están en la base de nuestra función de educadores. Enfrascados en el progreso de la tecnología, podemos descuidar la inestimable ayuda de la filosofía, aquella que intenta dar respuesta a los para qué, aquella que se adentra en el mundo de la ética y de los valores, en el mundo auténticamente humano. Obsesionados por el cómo intervenir, muchos docentes desatienden la cuestión capital del para qué actuar, del hacia dónde queremos dirigirnos. Con este artículo, hemos querido ante todo sensibilizar al profesorado sobre la importante responsabilidad que tienen en sus manos puesto que es un agente educativo de primer orden en la búsqueda de una sociedad mejor, formada por individuos autónomos, libres y solidarios con los otros, sea cual sea la cultura a la que pertenezcan.

Parece obvio que la democracia no puede ser entendida únicamente como una forma de gobierno; para ser real, para ser auténtica, debe significar un estilo de vida, afectar todos los modos de relación humana. Desde el punto de vista del individuo, la idea democrática consiste en tener una participación responsable conforme a la capacidad de formar y dirigir las actividades de los grupos de los cuales uno es miembro y contribuir a la realización de valores fundamentales, que nosotros podemos ver reflejados en la Declaración de los Derechos Humanos; desde el punto de vista de los grupos, ella demanda liberación de las potencialidades de los miembros de un grupo en armonía con los intereses y los bienes que son comunes.

La democracia no es, pues, un concepto meramente político, sino moral y necesita una instancia ética, de ahí la importancia que adquiere la educación en valores y en actitudes y que, para abordarla, hayamos examinado las teorías educativas de John Dewey. La ciudadanía se basa en un conjunto de vínculos, de compromisos con lo social, y se hace indispensable el aprendizaje y el ejercicio de unas ciertas disposiciones. Ahora bien, la educación cívico-moral no puede hacerse mediante lecciones, reglas aprendidas o simple enunciado de principios: se puede conocer, por ejemplo, el funcionamiento de las instituciones y ser un ciudadano deplorable. Lo necesario es desarrollar la práctica social. La educación ha de contribuir a la transmisión, comprensión y reflexión sobre las normas legales que regulan la vida en convivencia pero, sobre todo, también debe encargarse de la apropiación por los ciudadanos de las normas éticas, con la interiorización y aceptación personal de los fundamentos de la conducta moral, basada siempre en la autodeterminación. 
Nuestra mejor garantía de democracia es contar con unos individuos educados en los valores que conlleva, unos ciudadanos que estén formados en una cultura participativa, que conciban el diálogo como la estrategia más adecuada para solucionar los conflictos, que sean conscientes del respeto y tolerancia que todos nos debemos. A pesar de los años transcurridos desde su muerte, las propuestas de John Dewey para quien "the cause of democracy is the moral cause of the dignity and the worth of the individual" ${ }^{\prime \prime}$, nos parecen de una gran vigencia en nuestra "aldea planetaria".

\section{BIBLIOGRAFÍA}

APPLE, M.W.: El conocimiento oficial. La educación democrática en una era conservadora. Barcelona, Ed.Paidós, 1996.

ARANGUREN GONZALO, L.A. y SAEZ ORTEGA, P.: De la tolerancia a la interculturalidad. Un proceso educativo en torno a la diferencia., Madrid, Ed. AlaudaAnaya 1998.

BALLESTA, J., SANCHO, J. y AREA, M.: Medios de información y comunicación, escuela y sociedad, Murcia, Editorial K.R., 1998.

BERNAN, S., WANDERMAN, J., BRIONES, E. Y KURTINES, W.: "Education for Democracy: A co.constructivist perspective", Teoría de la Educación, vol. V. Eds Universidad de Salamanca, 1993, pp. 87-96.

CAMPS, V.: "La educación en valores ante el fin de siglo". En AAVV.: Educación y valores. Plasencia, AIDEX, 1996.

CAMPS, V.: "Educar para la democracia". Perspectivas, vol. XXVII, n4, diciembre 1997, 529-535.

CARR, W. y KEMMIS, S.: Teoría crítica de la enseñanza., Barcelona, Ed. Martínez Roca 1989.

CARR, W.: "Educación y democracia: ante el desafío postmoderno". En AAVV.: Volver a pensar la educación, vol. I., Madrid, Ed. Morata/Paideia 1995.

CHERRYHOLMES, C.H.: "(Re)clamación de pragmatismo para la educación". Revista de educación, n² 297, enero-abril 1992, pp. 227-261.

COMISION INTERNACIONAL SOBRE LA EDUCACION EN EL SIGLO XXI: La educación encierra un tesoro. Informe Delors., Madrid, Ed. Santillana-UNESCO 1996

CHILDS, J.L.: "Educational Philosophy of Dewey". The Philosophy of John Dewey. Ed. Paul Arthur Schilpp, 2a edición, La Salle, Illinois, Open Court, 1971.

DELEDALLE, G.: L'idée d'experience dans la philosophie de John Dewey. Presses Universitaires de France, Tunis, 1966.

DELVAL, J.: Los fines de la educación., Madrid, Ed. Siglo XXI 2a ed. 1993.

DEWEY, J.: The Collected Works of John Dewey, 1882-1953, editados por Jo Ann Boydston, Carbondale and Edwardsville: Southern Illinois University Press, 1969-1991.

DEWEY, J.: Problems of Men. New York, Ed Philosophical Library. Inc., 1946.

DEWEY, J.: El Público y sus problemas. Colección "Hombres y Problemas". Buenos Aires, Ed. Agora 1958.

DEWEY, J.: La reconstrucción de la filosofía., Buenos Aires Ed. Aguilar, 4a edición, 1970.

\footnotetext{
${ }^{60}$ DEWEY, J.: "Democracy and Education in the world of today". Problems of Men, New York, Philosophical Library In. 1946, p. 44. 
DEWEY, J.: Democracia y educación., Madrid, Ed. Morata 1995.

FISKE, J.: The Meaning of Infancy. Boston, 1909.

FREIRE, P.: La educación como práctica de la libertad., México, Ed. Siglo XXI, 15 edición, 1974.

GARRISON, J.: "A Deweyan Theory of Democratic listening", Educational Theory, Fall 1996, vol. 46, n4, 429-452.

GARRISON, J.: "Deweyan Pragmatism and the Epistemology of Comtemporary Social Constructivism", American Educational Research Journal, 34, n4, 1996, pp. 716740.

GIROUX, H.: Los profesores como intelectuales. Hacia una pedagogía crítica del aprendizaje., Barcelona, Ed. Paidós/MEC 1997

MARIE, J.B.: Les droits de l'homme ou "les choses de la vie" démocratique". Strasbourg, Direction des Droits de l'Homme, 1985.

MARTIN BONAFÉ, J.: "Poder y conciencia", Cuadernos de Pedagogía, nº 253, diciembre 1996, pp. 78-84.

MORDUCHOWICZ, R.: "La Educación para los Medios es una Educación para la Democracia", Comunicar, 13, 1999, pp. 110-120.

PÉREZ SERRANO, G.: Cómo educar para la democracia., Madrid, Ed. Popular ,1997.

RICE, S.: "Dewey's conception of "virtue" and its implications for Moral Education", Educational Theory, vol. 46, n³, Summer 1996, 269-282.

ROUSSEAU, J.J.: Emilio. Libro II,.., Madrid EDAF, 1972

SAVATER, F.: El valor de educar., Barcelona, Ed. Ariel 8ª edición, 1997.

TRIMARCHI, M.: "Il concetto di "tolleranza" contraddice il rispetto dei diritti umani", Cultura e Natura, n³, Roma, 1994, pp. 3-12.

WESTBROOK, R.B.: John Dewey and American Democracy. . New York Cornell University Press, Ithaca, , 1991

WESTBROOK, R.B.: "John Dewey (1859-1952)", Perspectivas. Grandes Educadores (número extraordinario en dos volúmenes), vol. I, 1994, pp. 289-305.

Datos de la autora

Dña. Virginia Guichot Reina

Doctora en Pedagogía por la Universidad de Sevilla

Profesora del Departamento de Teoría e Historia de la Educación y Pedagogía Social de la Universidad de Sevilla.

Dirección postal: Calle Malpartida 10-12, $1^{\circ}$ C; C.P. 41003 Sevilla, España

Dirección electrónica: guichot@us.es 